\title{
Interaction during feeding times between mothers and malnourished children under two years of age
}

\author{
Paula Chuproski Saldan ${ }^{1}$ \\ Renata Léia Demario \\ Marcela Komechen Brecailo ${ }^{1}$ \\ Maria das Graças Carvalho Ferriani ${ }^{2}$ \\ Débora Falleiros de Mello ${ }^{2}$
}

\footnotetext{
${ }^{1}$ Departamento de Nutrição, Universidade Estadual do Centro-Oeste. R. Camargo Varela de Sá 3, Vila Carli. 85040-080 Guarapuava PR Brasil. profpaulach@hotmail.com ${ }^{2}$ Departamento de Enfermagem Materno Infantil e Saúde Pública, Escola de Enfermagem de Ribeirão Preto, Universidade de São Paulo.
}

\begin{abstract}
This study sought to understand the relations between mothers and malnourished children at feeding times. It is an exploratory study with qualitative data analysis. Data collection was performed at home by means of participant observation with eight mother-child dyads and three grandmothers. Based on the thematic analysis, the following themes emerged: food and interaction; day-to-day care of the child. The families' life situation was unfavorable. Mothers and grandmothers were responsible for preparing family meals, feeding and child care. The mother-child relationships were permeated by gestures of affection, slaps, scolding, and threats during feeding and there were cases of negligence, physical and psychological violence in daily care. Some mothers and grandmothers spoke quietly and cared for the child to be fed and cleaned while others mothers showed little patience for dealing with the child and they became easily irritated. Mothers' life stories were marked by adverse events and most of them faced emotional problems that could have repercussions in relationships with children at feeding times and in daily care. The mother-child interactions at home do not always favor feeding and responsive care, which may further worsen the nutritional status of these children.

Key words Mother-child relations, Malnutrition, Infant care, Domestic violence
\end{abstract}




\section{Introduction}

Child malnutrition is one of the main causes of death in children under five years old ${ }^{1}$. In 33 years (1974-2007), Brazil had reduced the height for age deficit from $37.1 \%$ to $7.1 \%$. Despite this drop, the country still presents a height deficit thrice as high as that found in well-nourished populations ${ }^{2}$.

The macro-structural causes of malnutrition have been well documented in the literature, including the role of poverty, privation and correlated socioeconomic factors ${ }^{1,3}$. The microstructural level, on the other hand, has been less focused on in research, given its complexity and in function of the actual decrease in malnutrition. The caregiver's nutritional behaviors figure among the determinants of child malnutrition ${ }^{4}$.

Studies observe that the quality of the environment children live in influences their development $^{5-7}$. The environment and the relations established in early childhood influence the brain development of human beings, and the caregiver-child interactions that facilitate the children's social and emotional development include emotionally positive attitudes, sensitivity, responsiveness and the non-use of physical punishments. It should be highlighted that responsive feeding is also part of psychosocial childcare ${ }^{4-7}$.

Feeding is a basic need for children's physical growth, as important as the environment and responsive care ${ }^{4-5}$. When reconsidering the comprehensive child healthcare aspects, it is important to analyze the interaction of mothers and/or caregivers of malnourished children, apprehending their difficulties and experiences. Therefore, the objective of this study was to apprehend the relations between mothers and malnourished children under two years old during feeding practices at home, seeking support for child healthcare.

\section{Methods}

An exploratory study with qualitative data analysis $^{8}$. This design was chosen to capture the mother-child relations during feeding times in an environment that is common to them. The study was undertaken in Guarapuava, a city in the Central-South of the State of Paraná, Brazil.

To select the children, first, all children under two years old monitored at four health services in the peripheral region of the city were seen for an anthropometric assessment. For the purpose of this study, children with the anthropometric indices weight/age (W/A) and/or height/age (H/A) below the $3^{\text {rd }}$ percentile were included ${ }^{9}$.

The inclusion criteria adopted in this study were: children under two years old, malnourished, monitored at health services and mothers who stayed at home most of the time. The exclusion criteria were: premature children, with birth weight lower than $2500 \mathrm{~g}$, twins, suffering from other health problems, who attended kindergarten, received care from other caregivers than the mothers and mothers who worked outside their home. The study participants were eight mother-child dyads and three grandmothers. The grandmothers were included as research subjects because they were present during the observation of the child's feeding.

To collect the data, the participant observation technique was used ${ }^{10}$, focused on the mother-child relationships during the children's feeding times. The participant observation was conducted through weekly home visits to the children's homes, according to the time set by the mothers. On average, seven visits were made per child, totaling 56 home visits, taking one and a half to two hours each. Notes were made in a field diary ${ }^{8}$, highlighting the main points for the study focus, during and after each visit. The first author collected the data.

The data were submitted to thematic analysis $^{8}$, involving the digitalization and organization of all empirical material, during and after the data collection, in individual files. The interpretation of the field notes included the following steps, considered not as a temporal sequence of events here, but as different interwoven and mutually influential moments in the course of the research process $^{8}$ : a) preliminary reading of the material to map the subjects' actions and discourse; b) interpretation of the subjects' contents and positions; c) elaboration of interpretative synthesis, reviewing the contents in the light of the questions about the mother-child interaction during feeding times.

Approval for the study was obtained from the Research Ethics Committee at Universidade Estadual do Centro-Oeste (Unicentro), in Guarapuava-PR, in compliance with the Ministry of Health Ethical Standards and Guidelines in Resolution 196/96 ${ }^{11}$. The participating mothers and grandmothers signed the informed consent form. The notes taken from the eight field diaries are indicated as FD, followed by their respective number (FD1, FD2, ... FD8). 


\section{Results}

\section{Characteristics and life situation of the children and mothers}

The children were between 11 and 23 months old, including four girls and four boys, and were malnourished, four of them with a history of hospitalizations, mainly due to respiratory and intestinal infections. The mothers' age ranged between 16 and 39 years. Three of them were adolescents when their child was born. The maternal education level was low; two mothers were illiterate, five had up to eight years of education and one nine years. Two mothers were separated, two did not live with their partner as he lived in another state for work purposes and another because he was in prison and four mothers lived with the child's father. Five mothers had two children, two mothers had four children and one mother one child.

None of the mothers worked outside the home, but six of them had previously worked as a domestic servant, nanny and washerwoman and two mothers had never worked outside the home. One of the mothers indicated that she did not work because her partner would not let her, one of them because she had nobody to leave the child with, one helped her husband in the family bar next to the home and two were looking for a job.

Five mothers lived in their own house, three of which were located on land shared with other family members. Three mothers lived at the home of the children's mother grandparents. The houses were made of wood or bricks and had few rooms. One of the houses had no tap water, electric light and bathroom. Four families survived on the income from the fathers' work, three families on the income from the maternal grandparents' work or retirement and one family with the help of the Family Grant Program. The family income was not directly investigated, but the mothers and grandmothers indicated financial difficulties to purchase food during the month. Seven families were enrolled in the State Child Milk Program and three in the Family Grant Program.

Six mothers mentioned life histories marked by adversities. One of the mothers was pregnant at the time of the home visits, but hid the pregnancy from her maternal grandfather because the child's father was working in another state and she feared her grandfather's reaction. One of the mothers who was separated did not accept the separation and hoped for a reconciliation whenever the father visited the child. One lost her mother at the age of ten months and indicated that her father had different relationships and that the stepmothers used to treat her roughly. One of the mothers mentioned that her partner was in jail and that, sometimes, she took her son to prison to visit his father. One mother was worried because her oldest son, who was in prison for murder, had been released few days earlier and had returned home. One mother helped to raise two nephews, as her sister had passed away and one of the nephews was mentally ill.

Based on the interpretation of the field notes about the observation of the child's feeding practices, the results were grouped according to the following themes: Feeding and interaction; Daily childcare.

\section{Feeding and interaction}

The relations established between mothers and children during feeding were permeated by caresses (touching the face, kisses), conversations, screams, scolds, threats, promises and slaps. Some mothers demonstrated patience, calm and talked to the children mildly, while others got irritated easily when the children caused some mess while getting and yelled at the children, as follows:

While the mother served the child I observed caresses. She asked the child for a kiss. The child gently kissed the mother on the lips. The child moved around a lot in the chair while eating, the mother slapped the child several times and said: Have you got little animals on your but? The mother said she had to make lunch for the grandfather. She told her daughter: Stop, get up, come here (FD1).

For the child to eat the mother kept on inventing stories, talking about a girl who would come and eat her son's food, talked about taking him to see the tractor, threatened to give his food to his brother. She gave a spoon of food for the brother to eat, to see if the child would eat more (FD6).

Even the mothers who got easily upset, however, mentioned that, for the child to develop and grow appropriately, it was important to offer, besides food, love and kindness. The following field notes express these feelings:

[...] I think that the mother, the family, you have to give food at the right time, make sure there's enough food, and you have to take good care, because it also involves the mother's love for the child, it's not just filling the child with food and 
mistreating, thanks God I've never mistreated my child (FD4).

Ah good food, and treating the child well [...] It's taking good care of the child, for her to learn a lot, teach well, treat with a lot of kindness (FD8).

Some points the mothers raised when they offered the children food were: the child did not always eat when the food was offered, wouldn't stop eating, was always agitated, got distracted, ate, played a bit and then came back to eat and, sometimes, for the child to eat, you had to play with her. Through the field notes below, it was perceived that the mothers faced difficulties to deal with these situations:

The mother says that the child does not drink the entire bottle at once, he drinks a bit, plays, then drinks a bit more and so on, and always leaves a bit. The mother said: You need a lot of patience for small children to eat, sometimes they want to play, sometimes they want to eat (FD3).

The child started to walk with a piece of fried sausage in his hand and the mother said: $\mathrm{He}$ doesn't even stop to eat. She said that he likes to eat and walk around. I watched the child take a bit of food and go to the living room, then he returned to the children and ate some more. The mother said: To give him food you need to play with him (FD7).

\section{Daily childcare}

During the home visits, some of the mothers and grandmothers' general care for the children could be followed. This care included the children's hygiene, attention and interaction among mothers, grandmothers and children.

With regard to hygiene, care for the child's body was observed, mainly related to elimination. Not all children used disposable diapers. At some homes, the children used cloth diapers and, at others, the children walked around without diapers or just wearing clothes, eliminating feces and urine on the floor of the house or outside, in situations oriented by the mothers, and some children asked to go to the bathroom.

At some homes, the mothers and grandmothers demonstrated some urge to change the children with eliminations and were concerned with the cleanliness of the clothes and, for the girls, with the tidiness of their hair, as follows:

The grandmother is thoughtful and kind to her granddaughter. I don't see her yelling to the child. The child is always clean and has her hair tied.
[...] The grandmother called the mother for her to change the daughter, the mother went to the room and soon came with the changed child into the living room (FD2).

When I arrived at the house, I observed that the mother was sitting on the couch and the child in the stroller. The child had wet hair, had taken a bath and was wearing clean clothes, like during the other visits (FD8).

Some mothers did not change or wash the child as soon as (s)he had eliminated though. The child kept wearing dirty clothes and smelled bad for some time until the mother went to clean him/her. At some homes, the mothers fought, scolded and hit the children because they had shed urine or feces. Below are some field notes to demonstrate these behaviors:

The child pooped and the mother did not change her at that time. The smell was already perceptible and the mother asked the oldest sister to wait some more to change her because she might not have finished (FD4).

The child shed urine and feces in her pants. The mother slapped her daughter's bottom, lowered her pants and said: Uh, disgusting and, in the bathroom, called her daughter sloppy and a hog (FD1).

During the home visits, interactions between mothers and children could be observed and the way the children were treated:

The mother took her daughter on the lap and played with her, lowered her on her legs and kept on tickling her, the child giggled, then the mother put her on her lap to sleep and kept on caressing her daughter's head, until the child fell asleep. The mother is patient and talks to her daughter calmly (FD8).

During most visits, I watched the mother yell at her child, threaten to hit, slap, call the child shameless (FD5).

\section{Discussion}

In this study, the families' life situation, as evidenced by the children and mothers' characteristics, suggests a daily life permeated by socioeconomic difficulties. The children were exposed to the risk factors for malnutrition, such as the fact of being children of adolescent mothers, low maternal education, number of children, absence of the father from the home and insufficient income $^{1-3}$. Besides these factors, the repeated in- 
fection episodes aggravated the children's nutritional situation, an aspect that was also found in other studies ${ }^{1,2}$. These may not be the sole factors leading to the children's malnutrition, as the micro-environmental, also known as psychosocial risk factors, may have contributed to cause the malnutrition ${ }^{12}$. The mothers' life histories permitted apprehending the context in which the mother/grandmother-child interactions happened.

The people directly involved during feeding times and childcare were the mothers and grandmothers. It was observed that, since the selection of what would be prepared for the child, the preparation of the food and the distribution of the meal, family members were present, showing that the child has contact with the other, whether the mother, father, siblings or grandparents, through the food. Nevertheless, the mothers and grandmothers exclusively prepared the meals, fed and took care of the children. The male figure practicing these functions was not observed at any home.

Eating is not a solidary act, but a social activity that involves other people and a moment to create and maintain rich forms of sociability ${ }^{13}$. At the start of the development, nutrition is at the center of the mother-child interaction ${ }^{14,15}$. Besides the satisfaction of basic needs, this is a moment of learning and love, when it is important to talk and maintain visual contact with the child ${ }^{4}$. The success of this moment depends on both actors, that is, a mother sensitive to the child's needs and a child capable of manifesting his desires ${ }^{15}$.

The preparation of meals and childcare remains strongly linked to the female universe in the popular groups and reflects the sexual division of work ${ }^{13,16}$. In this study, the mothers did not work outside the home, some lived at the home of the children's grandparents, others lived with their husband who went out to work and were the provider and yet others lived alone with their children. The mothers and grandmothers were responsible for preparing the family meals, feeding and taking care of the children. In this study, the fathers and grandfathers' participation in childcare could not be witnessed. A study ${ }^{13}$ appoints that men's adherence to the art of cooking is limited to special occasions and that meal preparation remains a female task. It should also be highlighted that the women's insertion in the job market requires male participation in domestic life and childcare ${ }^{16}$.
Some tension characterized the feeding times at some homes, where the mothers demonstrated little patience to deal with the children and biased feelings were observed, permeated by caresses, slaps and scolds. The children eat slowly, get distracted easily, like playing with cutlery and food, make things dirty and the caregivers do not always understand and are not always prepared to cope with these situations $s^{4,17}$.

As observed, the mothers who got upset easily were the same who demonstrated affection for their child before and after some gesture, like slaps and scolds. The affective dimension of feeding, which involves the relation with the other, in this case the mothers/grandmothers with the children, is not only characterized by the positivity of harmonious relations and solidarity. On the opposite, the dichotomy constitutes the social relationships and the harmony does not eliminate the presence of conflict and vice-versa ${ }^{13}$.

The mothers seemed very busy with the preparation of family meals and did not have enough time to feed the children, who at the investigated homes ate before the adults and needed help, which explains the lack of patience with the children. Nevertheless, no type of aggression against the child at mealtimes is justified ${ }^{18}$. A study $^{19}$ about feeding strategies of mothers of malnourished and eutrophic children indicated that the domestic activities of preparing lunch and taking care of other children did not always interfere in care for the child during feeding times. That investigation discusses that the mother's limited engagement in this moment may be related to her physical and emotional condition, involving fatigue, weariness and low self-confidence $^{19}$. The mothers' life histories were marked by adversities, not only from the economic viewpoint, and the presence of emotional difficulties at some homes suggests a repercussion in the relations with the children during feeding and care.

The mothers and grandmothers faced some obstacles to feed the children, as they rarely remained quiet, did not eat at the time they had established or did not consume the amount of food they found necessary. When they started offering the meal, the mothers tried to talk or tell stories to entertain the child, but as the child refused to eat or did not remain still the mothers gave up. The mothers' feelings expressed in the statements reveal that the act of feeding the malnourished child was not seen as an easy task, but 
perceived the need for them to make efforts for this to happen, as the child got easily distract by other activities.

The child healthcare professionals can partially mitigate the mothers' difficulties during mealtimes. The professionals can advise the mothers and calm them down, explaining that children take more time to eat and get distracted easily ${ }^{17}$. They do not always eat when the adults want them to, as they may have consumed something close to mealtimes and children have a small gastric capacity ${ }^{20}$, which implies the refusal of food.

The person responsible for serving the child needs to watch what (s)he is eating without rushing; when the child stops eating, wait a bit and again offer food; offer food as soon as the child demonstrates (s) he is hungry, as waiting a lot can cause irritation and a loss of appetite ${ }^{17}$.

In addition, it is important to clarify that the mothers do not need to prepare a different meal for the child. The food can be the same as the family's, with slight modification $s^{20}$. That will help the mothers to control the time to prepare meals and increase their time to feed the child. It is fundamental for health professionals and women to be able to interact and exchange experiences and knowledge with a view to child health promotion and protection. These interactions are not simply a way of acting based on a priori knowledge though, but should be considered as a healthcare technology, in which it is important to discuss vital values that are not permanent, but involve always shared decisions about what actions can and should be accomplished at each moment, in each singular situation ${ }^{21}$.

The maternal reports evidence concern with the child's growth and development and that offering food is seen as a part of childcare, but that love, kindness and family life are as important as food. The mothers emphasized that taking care also means not practicing acts of violence against the children.

The maternal discourse summarizes the definition of responsive feeding, which involves care with the food that is prepared and offered to the child and assistance to offer the food. The child should be fed and encouraged to eat alone, without the use of verbal or physical enforcement, using utensils appropriate to the age and by people whom (s)he has a positive emotional relation with ${ }^{4}$.

In the case of malnourished children, the mother-child relation may be compromised in function of other than financial and social factors. Some authors ${ }^{12,22}$ highlight that the mothers' experiences can interfere in the bonding with their children, and situations like unwanted pregnancy, pregnancy rejected by the children's father, lack of family support and conditions experienced in childhood can be important to understanding the condition of malnutrition ${ }^{22}$. On the other hand, malnourished children may be even more attached to their mothers and their weaknesses, such as the fact of not eating and coping with stressful situations ${ }^{12}$.

Mealtimes can be used to introduce new words and concepts and, thus, stimulate the child's social and mental development ${ }^{4,5}$. The family members can mention names of utensils, foods, colors, show the children small and large things for them to get accustomed to size and talk about the flavor of foods ${ }^{4,17}$. This may not be feasible for families that do not have sufficient food and for mothers who are very busy with housework, taking care of other children and coping with emotional problems or stressful situations at home.

The care provided to the children at home included bodily hygiene, mainly related to eliminations of urine and feces, attention and interaction among mothers, grandmothers and children. Some children used cloth diapers or did not even use diapers, evidencing the families' social situation.

Some mothers and grandmothers took care to change the children rapidly in case of urine and feces. They also demonstrated concern with the cleanliness of clothes and, in case of girls, with the tidiness of their hair. At other homes, situations were observed in which the child with physical and mentally assaulted in case of eliminations in the clothes. At two homes where it was observed that the mothers and grandmothers changed the children more frequently, one of the children was an only child and the other had older siblings who did not demand that much attention from the mother. In these two cases, the context favored the children, as the mothers and grandmothers could give them more attention.

For the mothers and grandmothers, readily changing the child, wearing clean clothes and having tidy hair revealed an image that the child was well taken care of. Women can be recognized as good mothers through the care delivered to the children, with possible gender differences, that is, the girls demand more bodily care (clothing, hygiene, hairdressing, arrangement) 
under maternal supervision, while the boys need more control and dialogue, a task the father is left in charge of ${ }^{16}$. The visits of people external to the family core can also influence the mothers/ grandmothers in care and in the valuation of this social practice ${ }^{16}$.

The mothers and grandmothers should not be blamed for the situations observed at the homes. It should be kept in mind that motherhood does not exclude these mothers and grandmothers' limitations as human beings. It should be mentioned that the mothers in this study could be doing their best as mother/grandmother within their possibilities. Childcare can present a range of meanings, which each mother experiences according to her values and worldview ${ }^{23}$.

Some mothers may have had less access to a model and positive experience of motherhood than others, making it impossible for them to attend to their children's needs. To allow the caregivers to respond to the children's needs and interact with them, first, their needs should be attended to. In situations of lack of employment, housing and food and/or emotional problems, parents may experience difficulties to take care of their children ${ }^{12,22}$.

Small children are unable to execute certain tasks, such as eating alone, using the bathroom, accomplishing bodily hygiene, and need adults to help them. Depreciation of the children and physical violence were observed because of urinary and fecal eliminations, which may cause future problems, such as lack of elimination control and even traumas in the adult phase ${ }^{18}$.

The poverty situation makes it impossible for some mothers to envisage a future perspective, reducing their ability to decide, the use their potentials, making them lose interest in their own and their children's life ${ }^{12}$.

The moments of interaction among the mothers, grandmothers and children were intense and situations of physical, psychological violence and neglect were observed. The researcher's presence at the home did not influence the way they treated their children or grandchildren, demonstrating that this can be an attitude the aggressor finds normal. In a study ${ }^{19}$ that analyzed feeding times of malnourished and eutrophic children, no maternal verbal or physical aggression behavior was found, but they may have felt intimidated by the fact that they were being filmed or this was part of these mothers' common behavior.

Violence results from a combination of personal, family, social, economic, political and cul- tural factors ${ }^{18,24}$. Adults who practice acts of violence may have been assaulted as children or may have suffered some kind of violence when they were younger ${ }^{18}$. That is concerning, because it reveals an intergenerational problem. Normally, children act with other people in the same way as people act towards them, reproducing the violence or affection they receive ${ }^{25}$.

Identifying families that are vulnerable to violence (adolescent parents, low education, unemployment, marital separation, lack of affective bonds with the child, drugs use by family members) and periodical home visits can help to detect or prevent violence against the child. Community health agents play a crucial role in this work because they serve as the link between the community and the health service ${ }^{18,25}$.

The mothers and grandmothers were responsible for the acts of violence against the children, as they were the main caregivers and spent most of the time with the children/grandchildren. Infants and small children are more vulnerable to domestic violence, especially physical violence. Physical and psychological violence coexist at violent homes. In general, the aggressors are the people responsible for their care or other family members, given the children's limited social interaction beyond their home $\mathrm{e}^{18,24-26}$.

In prenatal, puerperal and childcare, health professionals play an important role in child protection, because mothers, babies and small children attend or are frequently taken to health services. Thus, the professionals can explain the importance of babies' initial contact and the care form with a view to appropriate development. In addition, the quality of the interactions between family members and children should be observed, explaining the importance of play and conversations ${ }^{25}$.

The families need to be prepared to acknowledge the children's development phases and demands, helping to reduce frustrations and enabling them to react to adversities. The parents and family members' good relationship with the children serve as a protection factor against violence. Affectionate and warm care acts as a protection factor in the development of the children's potentials ${ }^{25}$, besides reducing the problems of an unfavorable environment and adverse situations like infectious diseases and financial crises ${ }^{12}$.

It should be considered that the families of malnourished children who are facing severe social and emotional problems may not be able to solve the malnutrition problem alone. These 
families need intervention programs beyond income and food transference as, even when receiving monetary help and food, some families continue living with the malnutrition problem. Intervention programs that value the mothers' life histories and the family dynamics and which acknowledge the mother and family's potentials may be allies in coping with malnutrition ${ }^{12,27}$.

The mothers and grandmothers cannot only be considered as caregivers to the children, but also as people with feelings, life histories, culture and who interact with the world. Therefore, care for malnourished children should include care for the people responsible for caregiving, in the attempt to understanding their life dynamics and what this child represents to them and to the family ${ }^{16,23}$.

This study reports on the mothers, grandmothers and children's relationship at certain times during home visits in a contextualized relationship, and cannot be generalized to all poor families with malnourished children. Among the study limitations, it can be highlighted that only relations of mothers with malnourished children were observed at homes in unfavorable socioeconomic situations, without assessing the mothers' psychological aspects, problems or family conflicts, drugs use, presence of violence between partners, factors that could contribute to the mothers and grandmothers' violent attitudes against the children/grandchildren.

\section{Conclusion}

The children in this study were malnourished and came from families in poor socioeconomic situations, which by itself is considered an aggravating factor of malnutrition, as it deprives the child from appropriate nutrition. Besides this fact, most of the mothers had a life history marked by adversities and it was observed that the mother-child/grandmother-child interactions during feeding times and at other times during the home visits did not always favor feeding and responsive care, which could further aggravate these children's nutritional status.

Being present at the homes revealed that the maternal discourse differed from some mothers and grandmothers' attitudes when they reported that, for the children to grow and developed, love and kindness were needed, without acts of violence against them.

Poverty is considered one of the causes of violence against children, but it was observed that, even at homes with unfavorable conditions, the mothers did not practice acts of violence against the children, showing that other strategies were developed to overcome the social condition. This difference among the homes may indicate that other than financial and social factors may be related to the children's nutritional status, especially the mothers and grandmothers' psychological conditions and the life situations they face.

It is important for health professionals to be able to distinguish between the neglect of social privation that makes some families not have basic food items and childcare. As food is a core aspect of the mother-child interaction during the first months and years of life, it is fundamental to always consider the mother and family in childcare and to advise them about the importance of this relationship for the children's comprehensive development. 


\section{Collaborations}

PC Saldan worked on the conception, collection, analysis and interpretation of the data and writing of the article; RL Demario, MK Brecailo and MGC Ferriani on the analysis and interpretation of the data and writing of the article and DF Mello on the conception, analysis and interpretation of the data and critical review.

\section{References}

1. Black RE, Allen LH, Bhutta ZA, Caulfield LE, Onis M, Ezzati M, Mathers C, Rivera R. Maternal and child undernutrition: global and regional exposures and health consequences. Lancet 2008; 371(9608):243-260.

2. Victora CG, Aquino EML, Leal MC, Monteiro CA, Barros FC, Szwarcwald CL. Maternal and child health in Brazil: progress and challenges. Lancet 2011; 377(9780):1863-1876.

3. Monteiro CA, Benicio MHA, Konno SC, Silva ACF, Lima ALL, Conde WL. Causas do declínio da desnutrição infantil no Brasil, 1996-2007. Rev Saude Publica 2009; 43(1):35-43.

4. World Health Organization (WHO). Complementary feeding: report of the global consultation, and summary of guiding principles for complementary feeding of the breastfed child. Geneva: Department of Nutrition for Health and Development, WHO; 2002.

5. Irwin LG, Siddiqi A, Hertzman C. Early child development: a powerful equalizer. Vancouver: Commission on the Social Determinants of Health, World Health Organization; 2007.

6. Walker SP, Wachs TD, Grantham-McGregor S, Black MM, Nelson CA, Huffman SL, Baker-Henningham H, Chang SM, Hamadani JD, Lozoff B, Gardner JMM, Powell CA, Rahman A, Richter L. Inequality in early childhood: risk and protective factors for early child development. Lancet 2011; 378(9799):1325-1338.

7. Zamberlan MAT. Interação mãe-criança: enfoques teóricos e implicações decorrentes de estudos empíricos. Estud. psicol. (Natal) 2002; 7(2):399-406.

8. Minayo MCS. O desafio do conhecimento: pesquisa qualitativa em saúde. 9a ed. São Paulo: Hucitec; 2006.

9. Brasil. Ministério da Saúde (MS). Orientações para a coleta e análise de dados antropométricos em serviços de saúde. Brasília: MS; 2011.

10. Morse JM. What is the domain of qualitative health research? [editorial]. Qual Health Res 2007; 17(6):715717.

11. Brasil. Resolução no 196 de 10 de outubro de 1996. Dispõe sobre as diretrizes e normas regulamentadoras de pesquisas envolvendo seres humanos. Diário Oficial da União 1996; 10 out.

12. Solymos GMB. Vencendo a desnutrição: abordagem psicológica. $2^{a}$ ed. São Paulo: Salus Paulista; 2004.

13. Romanelli G. O significado da alimentação na família: uma visão antropológica. Medicina 2006; 39(3):333339.

14. Almeida GAN, Loureiro SR. Psicologia da alimentação. In: Ricco RG, Del Ciampo LA, Almeida GAN, organizadores. Puericultura: princípios e práticas - atenção integral à saúde da criança. São Paulo: Atheneu; 2000. p. $49-55$.

15. Satter EM. The feeding relationship. J Am Diet Assoc. 1986; 86(3):352-356.

16. Bustamante V, Trad LAB. Cuidando da saúde de crianças pequenas no contexto familiar: um estudo etnográfico com famílias de camadas populares. Cien Saude Colet 2007; 12(5):1175-1184.

17. World Health Organization (WHO). Complementary feeding: family foods for breastfed children. Geneva: WHO; 2000.

18. Pinheiro PS. Relatório mundial sobre violência contra crianças. Genebra: Organização das Nações Unidas; 2006. 
19. Perosa GB, Carvalhaes MABL, Benício MHD, Silveira FCP. Estratégias alimentares de mães de crianças desnutridas e eutróficas: estudo qualitativo mediante observação gravada em vídeo. Cien Saude Colet 2011; 16(11):4445-4464.

20. Brasil. Ministério da Saúde (MS). Dez passos para uma alimentação saudável: guia alimentar para crianças menores de dois anos um guia para o profissional de saúde na atenção básica. $2^{\mathrm{a}}$ ed. Brasília: MS; 2010.

21. Ayres JRCM. Cuidado: trabalho e interação nas práticas de saúde. Rio de Janeiro: CEPESC, IMS-UERJ, Abrasco; 2009.

22. Nudelmann C, Halpern R. O papel dos eventos de vida em mães de crianças desnutridas: o outro lado da desnutrição. Cien Saude Colet 2011; 16(3):1993-1999.

23. Paulo IMA, Madeira AMF. Ter um filho desnutrido: o significado para as mães. Rev. Min. Enf. 2006; 10(1):1217.

24. Devaney J. Chronic child abuse and domestic violence: children and families with long-term and complex needs. Child \& Family Social Work 2008; 13(4):443-453.

25. Brasil. Ministério da Saúde (MS). Linha de cuidado para atenção integral à saúde de crianças, adolescentes e suas famílias em situação de violências: orientação para gestores e profissionais de saúde. Brasília: MS; 2010.

26. Reichenheim ME, Souza ER, Moraes CL, Jorge MHPM, Silva CMFP, Minayo MCS. Violence and injuries in Brazil: the effect, progress made, and challenges ahead. Lancet 2011; 377(9781):1962-1975.

27. Sawaya AL, Solymos GMB, Florêncio TMMT, Martins PA. Os dois Brasis: quem são, onde estão e como vivem os pobres brasileiros. Estud. av. 2003; 17(48):21-45.

Article submitted 29/10/2013

Approved 30/03/2014

Final version submitted 07/04/2014 